* Doutor em Direito Político e Econômico pela Universidade Presbiteriana Mackenzie, Mestre em Direito Negocial pela Universidade Estadual de Londrina, Advogado e autor de livros

\section{DO DIREITO EMPRESARIAL COM O ADVENTO DA INOVAÇÃO.}

\author{
SNOWS. Of THE ENTERPRISE RIGHT WITH THE ADVENT OF \\ THE INNOVATION.
}

Fabio Fernandes Neves Benfatti*

Como citar: BENFATTI, Fabio Fernandes Neves. Do Direito Empresarial como advento da Inovação. Revista do Instituto de Direito Constitucional e Cidadania - IDCC, Londrina, v. 4, n. 1, p 41-55, ago, 2019. ISSN: 2596-0075.

https://doi.org/10.48159/revistadoidcc.v4n1.benfatti

Resumo: Analisa o Direito Empresarial, através do advento da legislação sobre a Inovação Lei 13243/2016; A adoção legislativa pela Teoria da Empresa. A unificação do Direito Privado. Verifica e Compara a transformação do Direito Comercial para o Direito Empresarial, bem como do comerciante para o empresário, através da criação de um novo standart jurídico, a Sociedade Empresária. Aponta como principais resultados: a) a obrigatoriedade da organização empresarial societária, b) objetivo da sociedade empresária voltada para o lucro, c) busca empresarial do bem comum, d) risco no equilíbrio do sistema através do neo-liberalismo, e) nos contratos comerciais, já havia extrutura empresarial antes do novo Código Civil Brasileiro. Conclui que a mudança foi positiva, do ponto de vista econômico, social, político, jurídico, legistativo e principalmente didático.

Palavras-chave: Direito Comercial/Empresarial;.Sociedade Empresária; Lei de Inovação

Abstract:It analyzes the Enterprise Right, through the advent of the new Brazilian Innovation, Law 13243/2016; The legislative adoption for the Theory of the Company. The unification of the Private law. It verifies and It compares the transformation of the Commercial law for the Enterprise Right, as well as of the trader 
for the entrepreneur, through the creation of new standart legal, the Society Entrepreneur. It points as main results: a) the obligatoriness of the societyária enterprise organization, b) objective of the society entrepreneur directed toward the profit, c) search enterprise of the common good, d) risk in the balance of the system through neoliberalism, e) in commercial contracts, already it had enterprise extructure before the new Brazilian Civil Code. It concludes that the change was positive, of the economic, social politician, point of view, legal, legislative and mainly didactic

Key-words: : Commercial/Enterprise;.Society Law Entrepreneur; Law Innovation 


\title{
DO DIREITO EMPRESARIAL COM O ADVENTO DA INOVAÇÃO
}

Figura principal do Direito Empresarial, é o empresário, que junto com a concepção de Sociedade Empresária, está previsto da seguinte forma no Código Civil, no artigo 966:

\begin{abstract}
"Considera-se empresário quem exerce profissionalmente atividade econômica organizada para a produção ou a circulação de bens ou de serviços.

Parágrafo único. Não se considera empresário quem exerce profissão intelectual, de natureza científica, literária ou artística, ainda com o concurso de auxiliares ou colaboradores, salvo se o exercício da profissão constituir elemento de empresa."
\end{abstract}

Há o requisito da profissionalidade na definição legal acima, logo, mesmo aquelas pessoas referidas no parágrafo único, se constituírem uma Sociedade Empresária, com organização empresarial, automaticamente tornam-se elementos da empresa, tornando-se empresários.

A Sociedade Empresária pode organizar-se, sob várias espécies de Sociedades, os tipos mais comuns são as Sociedades Anônimas, divididas em ações, constituídas através de estatuto, em regra para atividades de grande porte, e a Sociedade por quotas de Responsabilidade Limitada, dividida em quotas, constituída através de contrato social, e em regra para atividades de pequeno e médio porte.

Há ainda outros tipos societários, chamados menores, que trataremos nos próximos capítulos, mas independente do tipo societário, o Código Civil determina três obrigações das Sociedades Empresárias, que é registrar-se ${ }^{2}$, manter escrituração ${ }^{3}$ e demonstrações contábeis ${ }^{4}$.

Antes do início de suas atividades, a Sociedade Empresária deve requerer o seu registro ${ }^{5}$, conforme vislumbra-se no artigo 967 do Código Civil:

"É obrigatória a inscrição do empresário no Registro Público de Empresas Mercantis da respectiva sede, antes do início de sua atividade."

A falta de registro, ocasiona a responsabilidade ilimitada de quem as deveria registrar ${ }^{7}$, bem como de todos os sócios, pois essa Sociedade, ainda não registrada, é uma Sociedade de Fato.

Além de gerar a responsabilização dos sócios, em regra limitada, dependendo do tipo societário, o registro permite ainda a plena vigência do estatuto ou contrato social, habilitando

\footnotetext{
1 BRASIL, Institui o Código Civil, Lei 10406, de 10 de Janeiro de 2002, Diário Oficial da União, Brasília, DF, 11/01/2002, artigo 966.

2 Ibidem, art. 968.

3 Ibidem, artigos 1179 a 1195 .

4 Ibidem, artigos 1179 combinado com o artigo 1188.

5 Ibidem, artigos 968,985 e 1150 a 1154.

6 Ibidem, artigo 967.

7 Ibidem, Artigo 1151, $\S 3^{\circ}$.
} 
a Sociedade a sua regular atividade de buscar o seu objeto, seu ramo de atividade.

Logo, registra-se a Sociedade em busca de se alcançar a publicidade social, onde toda a coletividade, pelo menos em tese, ficaria sabendo que a Sociedade Empresária estaria operando, e qual o seu objeto, capital e sócios. ${ }^{8}$

Já o empresário rural, tem um tratamento diferente, caracterizando pela facultatividade em sua organização, optanto pela Sociedade Civil, ou pela Sociedade Empresária Rural, geralmente, o critério distintivo será o melhor aproveitamento econômico de sua atividade rural, de acordo com suas necessidades, ${ }^{9}$ se pequeno produtor, elegeria a primeira forma, se empresário na área do agronegócio, optaria pela segunda espécie, e portanto com organização empresarial.

Uma vez optando pelo regime empresarial sofrerá os seguintes efeitos: poderá declarar falência, pedir concordata, e terá livros contábeis, ou seja, todos os efeitos, dos empresários.

As sociedades empresárias, são declaradas inativas, após 10 anos, com base no artigo 60 da Lei 8934/94:

“Art. 60. A firma individual ou a sociedade que não proceder a qualquer arquivamento no período de dez anos consecutivos deverá comunicar à junta comercial que deseja manter-se em funcionamento." 10

A Capacidade Empresarial é assim como os demais tipos de capacidade espécie da Personalidade Humana, sendo sua medida, com a unificação privada se adquire diretamente aos 18 (dezoito) anos, artigo $5^{\circ}$, V do Código Civil, e aos 16 anos por emancipação ${ }^{11}$.

Há alguns casos ainda, que mesmo possuindo Capacidade Empresarial formal, tem-se óbices jurídicos, chamados incompatibilidades, com o exercício empresarial.

Os Deputados e Senadores não poderão, desde a posse serem proprietários, controladores ou diretores de empresa que goze de favor decorrente de contrato com pessoa jurídica de direito público, ou nela exercer função remunerada. ${ }^{12}$

Os Empregados, se a atividade for prejudicial a Sociedade Empresária no qual trabalhe. ${ }^{13}$.

O Falido, se houver sido condenado ou estiver respondendo a processo por crime falimentar, constituindo efeito da condenação por crime falimentar a interdição do exercício

8 Ibidem, art. 985.

9 lbidem, art. 970.

10 BRASIL, Dispõe sobre o Registro Público de Empresas Mercantis e Atividades afins e dá outras providências, Lei 8934, de 18 de Novembro de 1994, Diário Oficial da União, Brasília, DF, artigo 60.

11 BRASIL, Institui o Código Civil, Lei 10406, de 10 de Janeiro de 2002, Diário Oficial da União, Brasília, DF, $11 / 01 / 2002$, artigo $5^{\circ}$.

12 Artigo 54, BRASIL. Constituição (1988). Constituição da República Federativa do Brasil. Brasília, DF, 1988. 13 BRASIL, Consolidação das Leis do Trabalho, Decreto-Lei 5.452, de 1 de Maio 1943, artigo 482, a. 
do comércio, tornando-se efetiva logo que passe em julgado a sentença, sendo que a reabilitação extingue a interdição do exercício do comércio, mas somente pode ser concedida após o decurso de três ou de cinco anos, contados do dia em que termine a execução, respectivamente, das penas de detenção ou de reclusão, desde que o condenado prove estarem extintas por sentença as suas obrigações. ${ }^{14}$

ondenados por sentença transitada em julgado. ${ }^{15}$

Os Magistrados, considerados todos os Juízes, que façam parte como tal, dos quadros do Poder Judiciário, afinal o exercício da magistratura requer algum de isenção, que o exercício empresarial não permite. ${ }^{16}$ No mesmo sentido o membro do Ministério Público, ${ }^{17}$ por ser incompatível com um papel gerencial.

Estrangeiro com visto provisório de pais limitrofe, artigo 98 da Lei 8215/80:

"Ao estrangeiro titular de visto temporário e ao que se encontre no Brasil na condição do artigo $21, \S 1^{\circ}$, é vedado estabelecer-se com firma individual, ou exercer cargo ou função de administrador, gerente ou diretor de sociedade comercial ou civil, bem como inscrever-se em entidade fiscalizadora do exercício de profissão regulamentada." 18

O Servidor Público estatutário, nos termos do artigo 117, X, da Lei 8112/90:

"Ao servidor é proibido:

$\mathrm{X}$ - participar de gerência ou administração de empresa privada, de sociedade civil, ou exercer o comércio, exceto na qualidade de acionista, cotista ou comanditário;"

A atividade empresarial, como qualquer outra atividade, requer auxiliares de sua atividade, temos em regra, os auxiliares internos, e os

externos.

Os internos são os Prepostos, Gerentes e Empregados, e os externos, são os Vendedores e Viajantes pracistas.

Os Gerentes, são detentores de cargo de confiança, fidúcia, para com os Administradores, tem caráter permanente, ${ }^{19}$ poderes limitados através de contrato de trabalho, carta 14 BRASIL, Decreto-Lei 4661/45, de 21 de Junho de 1945. Lei de Falências. Artigos 138 e Artigos 195 a 197.

15 Artigo 1011, parágrafo $1^{\circ}$, BRASIL, Institui o Código Civil, Lei 10406, de 10 de Janeiro de 2002, Diário Oficial da União, Brasília, DF, 11/01/2002.

16 BRASIL, Lei Complementar, nº 35, Institui a Lei Orgânica da Magistratura Nacional, de 14 de Março de 1979 , artigo 36, I e II;

17 BRASIL, Lei Orgânica do Ministério Público, Lei 8625/93, de 12 de Fevereiro de 1993, artigo 44, III.

18 BRASIL, Define a situação Jurídica do estrangeiro no Brasil, cria o conselho nacional de imigração e da outras providencias, artigo 98.

19 BRASIL, Institui o Código Civil, Lei 10406, de 10 de Janeiro de 2002, Diário Oficial da União, Brasília, DF, 11/01/2002, art. 1172. 
de preposição, estatuto, contrato social, entre outros. E podem representar a Sociedade Empresária em Juízo. ${ }^{20}$

Já o Contador ou Guarda Livros, tem função importantíssima função na organização gerencial, pois auxiliam contabilmente, escrituram a Sociedade Empresária, podendo ser responsabilizados administrativamente no Conselho Regional ou Federal de Contabilidade.

Em regra a responsabilidade por atos do gerente e auxiliares é da Sociedade Empresária, porém terceiros podem ajuizar Oposição, perante arquivamento e averbação do instrumento no Registro Público de Empresas Mercantis, salvo se provado serem conhecidas da pessoa que tratou com o gerente. Para o mesmo efeito e com idêntica ressalva, deve a modificação ou revogação do mandato ser arquivada e averbada no Registro Público de Empresas Mercantis. ${ }^{21}$

Para a organização empresarial, é importantíssimo a escrituração de todos os atos sociais $^{22}$. Como Livro obrigatório, temos o Livro Diário (atualmente), exceto ao pequeno empresário $^{23}$, quando se trata de pequeno empresário optante pelo SIMPLES. Lei 9317/96²4, deverá ter apenas o livro caixa e Registro inventário.

Há ainda os Livros Especiais, só para alguns tipos de Sociedades Empresárias, ou eventos, como o Livro Registro de Empregados, ou o Livro Registro de Duplicatas.

Com relação a eficácia probatória, temos uma questão fronteiriça com a ciência afim do Direito Processual Civil, vejamos:

“Art. 378. CPC. Os livros comerciais provam contra o seu autor. É lícito ao comerciante, todavia, demonstrar, por todos os meios permitidos em direito, que os lançamentos não correspondem à verdade dos fatos.

Art. 379. CPC Os livros comerciais, que preencham os requisitos exigidos por lei, provam também a favor do seu autor no litígio entre comerciantes.

Art. 380. CPC A escrituração contábil é indivisível; se dos fatos que resultam dos lançamentos, uns são favoráveis ao interesse de seu autor e outros lhe são contrários, ambos serão considerados em conjunto como unidade.

Art. 333. CPC O ônus da prova incumbe:

I - ao autor, quanto ao fato constitutivo do seu direito;

II - ao réu, quanto à existência de fato impeditivo, modificativo ou extintivo do direito do autor.

20 Ibidem, artigo 1176.

21 Ibidem, artigo. 1.175. NCBB, "O preponente responde com o gerente pelos atos que este pratique em seu próprio nome, mas à conta daquele.

Art. 1.177. NCBB, Os assentos lançados nos livros ou fichas do preponente, por qualquer dos prepostos encarregados de sua escrituração, produzem, salvo se houver procedido de má-fé, os mesmos efeitos como se o fossem por aquele. No exercício de suas funções, os prepostos são pessoalmente responsáveis, perante os preponentes, pelos atos culposos; e, perante terceiros, solidariamente com o preponente, pelos atos dolosos."

22 Ibidem, artigo. 1.178. "Os preponentes são responsáveis pelos atos de quaisquer prepostos, praticados nos seus estabelecimentos e relativos à atividade da empresa, ainda que não autorizados por escrito. Quando tais atos forem praticados fora do estabelecimento, somente obrigarão o preponente nos limites dos poderes conferidos por escrito, cujo instrumento pode ser suprido pela certidão ou cópia autêntica do seu teor."

23 Ibidem, artigo art. 1179.

24 BRASIL, Dispõe sobre o regime tributário das microempresas e das empresas de pequeno porte, institui o sistema integrado de pagamento de impostos e contribuições das microempresas e das empresas de pequeno porte - simples e da outras providencias, Lei 9317/96, de 05 de Dezembro de 1996. 
Parágrafo único. É nula a convenção que distribui de maneira diversa o ônus da prova quando:

I - recair sobre direito indisponível da parte;

II - tornar excessivamente difícil a uma parte o exercício do direito. “25

Logo, a falta de escrituração tem como efeitos, a presunção de veracidade dos fatos alegados pela adversa, indício de crime falimentar, bem como não poder pedir concordata, ou a verificação de contas.

Além da escrituração, a Sociedade Empresária deve providenciar o seu registro, através do requerimento de inscrição ${ }^{26}$.

A inscrição tem como finalidades da inscrição, o disposto na lei 8934/94, em seu artigo $1^{\circ}$, I, senão vejamos:

I - dar garantia, publicidade, autenticidade, segurança e eficácia aos atos jurídicos das empresas mercantis, submetidos a registro na forma desta lei;

II - cadastrar as empresas nacionais e estrangeiras em funcionamento no País e manter atualizadas as informações pertinentes;

III - proceder à matrícula dos $\mathrm{ag}^{27}$ entes auxiliares do comércio, bem como ao seu cancelamento.

Mas cuidado, os atos das sociedades civis, associações, fundações são registrados no Registro Civil de Pessoas Jurídicas, já os atos das firmas empresariais (mercantis) individuais e das sociedades empresárias (mercantis), são arquivados no Registro Público de Empresas Mercantis.

As Juntas Comerciais são órgãos locais (Estaduais), com função executora e administradora dos serviços de registro. ${ }^{28}$ Subordina-se ao governo do estado.

Tendo como proibições de arquivamento, os casos do artigo artigo 30 da Lei

$934 / 94^{29}$.

25 BRASIL, Institui o Código de Processo Civil, Lei 5869, de 11 de Janeiro de 1973, artigo 333 e 378 seq.

26 BRASIL, Institui o Código Civil, Lei 10406, de 10 de Janeiro de 2002, Diário Oficial da União, Brasília, DF, 11/01/2002, artigo 968.

27 BRASIL, Dispõe sobre o Registro Público de Empresas Mercantis e Atividades afins e dá outras providências, Lei 8934, de 18 de Novembro de 1994, Diário Oficial da União, Brasília, DF, artigo $1^{\circ}$.

28 Ibidem. art. $3^{\circ}$, II c/c art. 5. "Art. $3^{\circ}$ Os serviços do Registro Público de Empresas Mercantis e Atividades Afins serão exercidos, em todo o território nacional, de maneira uniforme, harmônica e interdependente, pelo Sistema Nacional de Registro de Empresas Mercantis (Sinrem), composto pelos seguintes órgãos:

I - o Departamento Nacional de Registro do Comércio, órgão central Sinrem, com funções supervisora, orientadora, coordenadora e normativa, no plano técnico; e supletiva, no plano administrativo;

II - as Juntas Comerciais, como órgãos locais, com funções executora e administradora dos serviços de registro.

Art $5^{\circ}$ Haverá uma junta comercial em cada unidade federativa, com sede na capital e jurisdição na área da circunscrição territorial respectiva."

29 Ibidem, artigo 30. 
A Sociedade Empresária deve ainda proceder a demonstrações contábeis periódicas e com base no livro diário. ${ }^{30}$ Sendo que a periodicidade é em regra anual, mas pode ser menor.

O fato de não se fazer as demonstrações contábeis terá como conseqüências, o indício de crime falimentar, a dificuldade de acesso a empréstimo, não poderá participar de licitação, não poderá pedir concordata, e os administradores respondem ilimitadamente.

A noção de estabelecimento empresarial, está prevista no artigo 1142 do Código

Civil:

"Considera-se estabelecimento todo complexo de bens organizados, para exercício da empresa, por empresário, ou por sociedade empresária." 31

Trata-se do conjunto de bens voltados para a atividade econômica, tais como o estoque, máquinas, veículos, tecnologia, marcas e outros sinais distintivos. "Art. 1.155. NCCB. Considera-se nome empresarial a firma ou a denominação adotada, de conformidade com este Capítulo, para o exercício de empresa.

Parágrafo único. Equipara-se ao nome empresarial, para os efeitos da proteção da lei, a denominação das sociedades simples, associações e fundações." ${ }^{32}$

Todos os elementos que agregam um sobre-valor aos bens, fazendo parte de um conjunto harmônico, também fazem parte da noção de estabelecimento empresarial tais como, o serviço, o know how, o investimento.

Esse sobre valor é reconhecido pelo direito, p. ex. quando na desapropriação permite a indenização do imóvel ao possuidor indireto (proprietário) e o possuidor direto (locatário).

No Direito Comparado temos como termos sinônimos, goodwill of a trade, fundo de comércio (funds de commerce), aviamento (avviamento), fundo de empresa.

Contudo, boa parte da doutrina entende que estabelecimento é só o conjunto de bens, já o fundo de empresa é todos os elementos que de alguma forma valorizam economicamente o empreendimento agregando valor por exemplo.

A Sociedade Empresária pode ter vários estabelecimentos, dotando uma como sede, as demais como filiais, geralmente a matriz é o primeiro estabelecimento, não a sede, por exemplo a Matriz é a agência 001 Bradesco, em Marília, sendo a Sede Agencia Cidade de Deus em Osasco.

A natureza do Estabelecimento Empresarial, é de uma res (coisa), com proteção através dos Direitos Reais, logo o Estabelecimento empresarial não é sujeito de direito, apenas integra o patrimônio da Sociedade Empresária.

Assim, o estabelecimento empresarial é diferente da Sociedade Empresária (Sujeito de Direitos), e Empresa (atividade econômica), tendo como elementos, bens Corpóreos e Incorpóreos.

30 BRASIL, Institui o Código Civil, Lei 10406, de 10 de Janeiro de 2002, Diário Oficial da União, Brasília, DF, 11/01/2002. artigo 1188 .

31 Ibidem, artigo 1142 .

32 Ibidem, artigo 1155. 
São Corpóreos, por exemplo, o estoque, mobiliários, utensílios, veículos, máquinas; E Incorpóreos, a patente de invenção, modelo de utilidade, registro de desenho industrial, marca registrada, nome empresarial, título de estabelecimento, ponto;

Doutrina majoritária não considera: potencial de ponto, banco de clientes e dívidas como elementos do estabelecimento.

Ponto, é o local onde se encontra o estabelecimento empresarial. A proteção jurídica do ponto decorre da sua importância para o sucesso da empresa.

A Sociedade Empresária pode ter vários estabelecimentos, alguns com o ponto alugado outros próprios - p.ex. Banco Bradesco (não aluga), Lojas Americanas - Aluga o ponto.

Na locação empresária, há o interesse razoável de manter o ponto, assim é necessária a proteção à manutenção do ponto.

Já a Sociedade Empresária proprietária do imóvel onde se localiza o ponto, a proteção jurídica faz-se pelo direito de propriedade.

Quando a Sociedade Empresária é locatária, a proteção faz-se pela posse direta com base na Lei de locação $8245 / 91^{33}$, através da Ação Renovatória. ${ }^{34}$

São requisitos da Ação Renovatória:

"Da locação não residencial, Lei 8245/91.

Art. 51. Nas locações de imóveis destinados ao comércio, o locatário terá direito a renovação do contrato, por igual prazo, desde que, cumulativamente:

I - o contrato a renovar tenha sido celebrado por escrito e com prazo determinado; II - o prazo mínimo do contrato a renovar ou a soma dos prazos ininterruptos dos contratos escritos seja de cinco anos;

III - o locatário esteja explorando seu comércio, no mesmo ramo, pelo prazo mínimo e ininterrupto de três anos.

$1^{\circ} \mathrm{O}$ direito assegurado neste artigo poderá ser exercido pelos cessionários ou sucessores da locação; no caso de sublocação total do imóvel, o direito a renovação somente poderá ser exercido pelo sublocatário.

$2^{\circ}$ Quando o contrato autorizar que o locatário utilize o imóvel para as atividades de sociedade de que faça parte e que a esta passe a pertencer o fundo de comércio, o direito a renovação poderá ser exercido pelo locatário ou pela sociedade.

$3^{\circ}$ Dissolvida à sociedade comercial por morte de um dos sócios, o sócio sobrevivente fica sub - rogado no direito a renovação, desde que continue no mesmo ramo.

$4^{\circ} \mathrm{O}$ direito a renovação do contrato estende - se às locações celebradas por indústrias e sociedades civis com fim lucrativo, regularmente constituídas, desde que ocorrentes os pressupostos previstos neste artigo.

$5^{\circ}$ Do direito a renovação decai aquele que não propuser a ação no interregno de um ano, no máximo, até seis meses, no mínimo, anteriores à data da finalização do prazo do contrato em vigor." 35

33 BRASIL, Dispõe sobre as locações dos Imóveis urbanos e os procedimentos a eles pertinentes, Lei 8245/91, de 18 deOutubro de 1991.

34 Trata-se do exercício do Direito de Ação, onde a Sociedade Empresária é o autor, e o Locador (ou Proprietário), é o réu.

35 Ibidem, artigo 51. 
Logo, temos três requisitos, o formal, que é o prazo determinado, o temporal, que é de 5 (cinco) anos, mesmo somados, e o material, que é a mesma atividade econômica por 3 (três) anos.

\title{
Exceção de Retomada, previsto no art. 52 e 72, II e III da Lei de Locação
}

8245/91:

\begin{abstract}
“Art. 52. O locador não estará obrigado a renovar o contrato se:
I - por determinação do Poder Público, tiver que realizar no imóvel obras que importarem na sua radical transformação; ou para fazer modificações de tal natureza que aumente o valor do negócio ou da propriedade;

II - o imóvel vier a ser utilizado por ele próprio ou para transferência de fundo de comércio existente há mais de um ano, sendo detentor da maioria do capital o locador, seu cônjuge, ascendente ou descendente.

$1^{\circ} \mathrm{Na}$ hipótese do inciso II, o imóvel não poderá ser destinado ao uso do mesmo ramo do locatário, salvo se a locação também envolvia o fundo de comércio, com as instalações e pertences.

$2^{\circ}$ Nas locações de espaço em shopping centers, o locador não poderá recusar a renovação do contrato com fundamento no inciso II deste artigo.

$3^{\circ} \mathrm{O}$ locatário terá direito a indenização para ressarcimento dos prejuízos e dos lucros cessantes que tiver que arcar com mudança, perda do lugar e desvalorização do fundo de comércio, se a renovação não ocorrer em razão de proposta de terceiro, em melhores condições, ou se o locador, no prazo de três meses da entrega do imóvel, não der o destino alegado ou não iniciar as obras determinadas pelo Poder Público ou que declarou pretender realizar.
\end{abstract}

Art. 72. A contestação do locador, além da defesa de direito que possa caber, ficará adstrita, quanto à matéria de fato, ao seguinte:

II - não atender, a proposta do locatário, o valor locativo real do imóvel na época da renovação, excluída a valorização trazida por aquele ao ponto ou lugar;

III - ter proposta de terceiro para a locação, em condições melhores,"36

A alienação do estabelecimento empresarial, também é conhecida com trespasse, trata-se da venda de todo o estabelecimento, com os bens corpóreos e incorpóreos.

A Sociedade Empresária pode vender um estabelecimento ou vários estabelecimentos.

Diferente de quando vende só as quotas ou ações, nesse caso vende a própria

Sociedade.

Questão importante é se determinar à responsabilidade pelo passivo, antes de 2002, o comprador só se responsabilizava pelas dívidas do contrato, fiscais e trabalhistas.

Agora, a matéria tem tratamento específico no Código Civil, onde o adquirende

36 Ibidem, artigo 72. 
apenas responde pelos débitos que forem regularmente contabilizados, logo, valorizou-se de alguma forma, a figura do Contador, vejamos então o artigo 1146 do Código Civil:

Art. 1.146. O adquirente do estabelecimento responde pelo pagamento dos débitos anteriores à transferência, desde que regularmente contabilizados, continuando o devedor primitivo solidariamente obrigado pelo prazo de um ano, a partir, quanto aos créditos vencidos, da publicação, e, quanto aos outros, da data do vencimento. ${ }^{37}$

Além do mais, os efeitos do Novo Código Civil, não retroagem no tempo, pois tratam-se de compra e venda de estabelecimento empresarial, que se constituiu em negócio jurídico perfeito, ou seja, esgotou-se no âmbito do antigo código, não retroagindo.

A venda do estabelecimento empresarial somente terá proteção em face terceiros de boa fé, característica em destaque no novo sistema, se ocorrer a sua averbação no cartório competente, esse dispositivo tem como objetivo, a publicidade nos negócios jurídicos, e a segurança jurídica que provoca para os contratantes.

Art. 1.144. O contrato que tenha por objeto a alienação, o usufruto ou arrendamento do estabelecimento, só produzirá efeitos quanto a terceiros depois de averbado à margem da inscrição do empresário, ou da sociedade empresária, no Registro Público de Empresas Mercantis, e de publicado na imprensa oficial. ${ }^{38}$

Mas a eficácia do negócio jurídico não é automática, caso haja a existência de dívidas, para surtir efeito o negócio jurídico é necessário que sejam avisados todos os credores, e que haja a anuência de todos.

Art. 1.145. Se ao alienante não restarem bens suficientes para solver o seu passivo, a eficácia da alienação do estabelecimento depende do pagamento de todos os credores, ou do consentimento destes, de modo expresso ou tácito, em trinta dias a partir de sua notificação. ${ }^{39}$

Não cumprindo os requisitos acima, e ocorrendo a decretação da falência, o adquirente perde para a massa falida o estabelecimento, em caso da decretação de falência.

Art. 52. Não produzem efeitos relativamente à massa, tenha ou não o contratante conhecimento do estado econômico do devedor, seja ou não intenção deste fraudar credores:

37 BRASIL, Institui o Código Civil, Lei 10406, de 10 de Janeiro de 2002, Diário Oficial da União, Brasília, DF, $11 / 01 / 2002$, artigo 1146 . 38 Ibidem, artigo 1144.

39 Ibidem, artigo 1145. 
VIII - a venda, ou transferência de estabelecimento comercial ou industrial, feita sem o consentimento expresso ou o pagamento de todos os credores, a esse tempo existentes, não tendo restado ao falido bens suficientes para solver o seu passivo, salvo se, dentro de trinta dias, nenhuma oposição fizeram os credores à venda ou transferência que lhes foi notificada; essa notificação será feita judicialmente ou pelo oficial do registro de títulos e documentos. ${ }^{40}$

Com relação aos débitos laborais e fiscais, não houve mudança, uma vez que são tratados em leis específicas, que não tiveram repercussão, pelo menos nessa questão, com o advento do novo código civil, logo o adquirente responde sempre pelas dívidas trabalhistas e fiscais.

Art. 448. A mudança na propriedade ou na estrutura jurídica da empresa não afetará os contratos de trabalho dos respectivos empregados. ${ }^{41}$

Art. 133. A pessoa natural ou jurídica de direito privado que adquirir de outra, por qualquer título, fundo de comércio ou estabelecimento comercial, industrial ou profissional, e continuar a respectiva exploração, sob a mesma ou outra razão social ou sob firma ou nome individual, responde pelos tributos, relativos ao fundo ou estabelecimento adquirido, devidos até à data do ato:

I - integralmente, se o alienante cessar a exploração do comércio, indústria ou atividade;

II - subsidiariamente com o alienante, se este prosseguir na exploração ou iniciar dentro de seis meses a contar da data da alienação, nova atividade no mesmo ou em outro ramo de comércio, indústria ou profissão. ${ }^{42}$

Estabelecimento em imóvel alugado - em qualquer caso tem que negociar com o proprietário do imóvel. Artigo 13 da Lei 8245/91:

A transferência de propriedade tem ainda repercussões quando o estabelecimento empresarial localiza-se em imóvel alugado, nesse caso, o locador além de ser notificado, não pode ter o seu direito de propriedade abalado de forma alguma, mesmo que possua a posse indireta do bem.

Art. 13. A cessão da locação, a sublocação e o empréstimo do imóvel, total ou parcialmente, dependem do consentimento prévio e escrito do locador.

$1^{\circ} \mathrm{Não}$ se presume o consentimento pela simples demora do locador em manifestar formalmente a sua oposição.

$2^{\circ}$ Desde que notificado por escrito pelo locatário, de ocorrência de uma das hipóteses deste artigo, o locador terá o prazo de trinta dias para manifestar

40 BRASIL, Institui a Lei de Falências, Decreto-Lei no 7.661 de 21 de junho de 1945, artigo, 52.

41 BRASIL, Consolidação das Leis do Trabalho, Decreto-Lei 5.452, de 1 de Maio 1943, artigo 448.

42 BRASIL, Dispõe sobre o sistema tributário nacional e institui normas gerais de direito tributario aplicaveis a união, estados e municipios, Lei 5172, de 25 de Outubro de 1966, artigo 133. 
formalmente a sua oposição. ${ }^{43}$

Após a sua notificação, pode concordar expressa ou tacitamente, em não concordando, rescinde o contrato a qualquer momento.

Repugnante é a concorrência, entre o alienante e o comprador do estabelecimento, pois o alienante do estabelecimento só pode estabelecer prática que configure concorrência, se permitido no contrato de compra e venda do estabelecimento, por força da disponibilidade do direito, o alienante pode vir a ser demandado por enriquecimento ilícito do alienante para com o adquirente (comprador) do estabelecimento, deve se verificar o caso concreto.

Art. 1.147. Não havendo autorização expressa, o alienante do estabelecimento não pode fazer concorrência ao adquirente, nos cinco anos subseqüentes à transferência.

Parágrafo único. No caso de arrendamento ou usufruto do estabelecimento, a proibição prevista neste artigo persistirá durante o prazo do contrato.

O nome do estabelecimento não se confunde com o nome da Sociedade Empresária, Requião ${ }^{44}$ define com sendo insígnia - local onde o empresário expõe suas mercadorias e se encontra com a clientela.

Permite-se que cada estabelecimento tenha um nome, contudo, por uma questão de publicidade e mídia, as Sociedades Empresárias preferem usar apenas um nome para todos os seus estabelecimentos, o Banco Itaú S/A, é o Nome da Sociedade Empresária, já Itaú é o nome dos estabelecimentos (que são as agências do Banco).

Segundo o Código Civil Português, "insígnia como qualquer sinal externo, composto de figuras ou desenhos simples ou combinados, com o nome do estabelecimento, ou com outras palavras ou divisas, contanto que no conjunto sobreleve a forma ou configuração específica, como elemento distintivo e característico".

Assim, a legislação portuguesa, diferencia insígnia de nome do estabelecimento, a distinção na legislação nacional ocorria na época da vigência do Decreto-Lei no $1005 / 69$, que foi revogado pelo Código de Propriedade Industrial Lei 5772/71.

No ordenamento jurídico nacional não há proteção legal específica, mas trata-se de concorrência desleal o uso do nome do estabelecimento ou insígnia.

A exemplo do que ocorre com o ponto, denominação de fantasia, figuras, emblemas, a cessão e transferência, são vendidas junto com o estabelecimento, todavia, Requião defende a possibilidade da venda, sendo que a maior parte da doutrina discorda.

Requisitos do Registro do estabelecimento e insígnia, (requisitos da revogada

43 BRASIL, Dispõe sobre as locações dos Imóveis urbanos e os procedimentos a eles pertinentes, Lei 8245/91, de 18 deOutubro de 1991, artigo, 13.

44 REQUIÃO, Rubens. Curso de Direito Comercial, V.1, São Paulo, Saraiva, 2003, p. 289. 
Legislação, Decreto-Lei $n^{0}$ 1005/69), temos a originalidade e o nome apropriado.

Nomes não registráveis, através revogada Legislação, Decreto-Lei no 1005/69. temos os nomes ligados a terceiros, como ocorre quando se coloca os seguinte sufixos: o antigo armazém, antiga fábrica, sucursal, filial, depósito, ou antigo empregado, antigo chefe, antigo gerente, sucessor.

O Decreto-Lei $n^{\circ} 1005 / 69$, apesar de revogado, é um daqueles casos que tem influência jurisprudencial, até hoje, sendo uma referência importantíssima.

\section{CONCLUSÃO.}

Conclui-se que a Inovação prevista na Lei 13243/2016, influencia na unificação do Direito Privado, na busca do chamado empresário pelo "lucro" estreitou ainda mais os laços do Direito Civil, com o Direito Empresarial, facilitando a aplicação, da chamada teoria geral do Direito Privado, e junto toda a riqueza do Direito Romano, Obrigações, Reais, Família, entre outros.

Logo, o Direito Comercial, rebatizado agora de Direito Empresarial, através da unificação privada, tem ao lado de mecanismos tradicionais do Direito, ambição suficiente, para solucionar os novos desafios inovadores que a humanidade exigir.

\section{REFERÊNCIAS}

ALMEIDA, Amador Paes de. Manual das sociedades comerciais. 13 ${ }^{\text {a }}$ ed, São Paulo: Saraiva, 2003.

. Manual das Sociedades Anônimas. São Paulo : Saraiva, 1999.

. Teoria e prática dos Títulos de Crédito - São Paulo: Saraiva.

ALMEIDA, João Batista de. A Proteção Jurídica do Consumidor. $2^{\mathrm{a}}$ edição rev., atualizada e ampliada. São Paulo: Saraiva, 2000.

ALVIM, Arruda. Tratado de Direito Processual Civil, Vol. 2. $2^{\mathrm{a}}$ ed. São Paulo, RT, 1996.

AZEVEDO, Álvaro Villaça. Teoria Geral dos Contratos Típicos e Atípicos. São Paulo: RT.

BENFATTI, Fábio Fernandes Neves. Direito ao Desenvolvimento. São Paulo, Saraiva, 2014.

BITTAR, C. A . -Contratos Comerciais. Rio de Janeiro : Forense, 1998

BOBBIO, Norberto. Teoria do Ordenamento Jurídico. Tradução Maria Celeste C. J. Santos. 10. ed. Brasília: Editora Universidade de Brasília, 1999.

BULGARELLI, Waldirio. - O direito das Empresas. São Paulo : ed; RT. 1980 . - Questões Contratuais no Código de Defesa do Consumidor. São Paulo Atlas. 
COELHO, Fábio Ulhoa. - Curso de Direito Comercial. Vol. $1.7^{\text {a }}$ ed. São Paulo: Saraiva, 2003. . - Curso de Direito Comercial. Vol. 1 . 6a ed. São Paulo: Saraiva, 2003. . - Curso de Direito Comercial. Vol. 1. $3^{\text {a }}$ ed. São Paulo: Saraiva, 2003. . - Manual de Direito Comercial. 14ª ed. São Paulo: Saraiva, 2003.

DINIZ, Maria Helena - Tratado teórico e prático dos contratos. São Paulo: Saraiva.

KELSEN, Hans. Teoria Geral do Direito e do Estado. Tradução Luís Carlos Borges. 3. ed. São Paulo: Martins Fontes, 1998.

MARTINS, Fran - Curso de Direito Comercial -Rio de Janeiro; Forense, 2001. , Fran - Contratos e Obrigações Comerciais. Rio de Janeiro; Forense

MARQUES, Cláudia Lima - Contratos no Código de Defesa do Consumidor - São Paulo; RT.

MEIRELLES, Hely Lopes. Direito Administrativo Brasileiro. 26. ed. São Paulo: Malheiros Editores, 2001.

NEGRÃO, Ricardo, - Manual de Direito Comercial e de Empresa. $1^{\text {o }}$ vol. $3^{\mathrm{a}}$ ed. - São Paulo, Saraiva, 2003.

NUNES, Luiz Antônio - Empresa e Código de Defesa do Consumidor - São Paulo; Artpress.

PEREIRA, Alexandre Libório Dias. Comércio Electrónico na Sociedade da Informação: da Segurança Técnica à Confiança Jurídica. Coimbra: Livraria Almedina, 1999.

PEREIRA, Caio Mário da Silva, Lesão nos Contratos. Rio de Janeiro: Forense.

RECHSTEINER, Beat Walter - Direito Internacional Privado: Teoria e Prática - $6^{\mathrm{a}}$ ed. São Paulo, Saraiva, 2003.

REQUIÃO, Rubens. - Curso de Direito Comercial. $1^{\circ}$ vol. 25 ed. São Paulo : Saraiva, 2003. . - Curso de Direito Comercial. $2^{\circ}$ vol. 23 ed. São Paulo : Saraiva, 2003.

SZANIAWSKI, Elimar. Direitos da Personalidade e sua Tutela. São Paulo: RT, 1993.

Recebido em: 23/04/2019.

Aprovado em: 23/05/2019. 